\title{
Soft Skills and Job Opportunities of Migrants: Systemic Relationships in the Labor Market
}

\author{
Roland Bardy \\ PhD, MBA, Florida Gulf Coast University, USA; Wittenberg Center for Global Ethics, Germany
}

Arthur Rubens

PhD, Florida Gulf Coast University, USA

Paul Eberle

$\mathrm{PhD}$, Florida Southern College, USA

\begin{abstract}
The skills of migrants, the skills of existing workers, and the characteristics of the host economy are critical factors that impact the labor market in any country. Studying these effects is a critical area of research with much of the research being specific to time and place. There are studies on the UK which look into the wage effects of immigration and the impact on unemployment A study on Denmark found that an increase in the supply of refugee-country immigrants pushed less educated native workers (especially the young and lowtenured ones) to pursue less manual-intensive occupations. So, immigration had positive effects on unskilled wages, employment and occupational mobility. This has led to critical assessments of the skills brought in by migrants who have a higher level of education. This is occurring to quite an extent in present-day immigration to Europe.
\end{abstract}

This paper draws on a study performed by the authors on African nationals with an academic background and who study, live and work in Germany. They were asked to complete an online questionnaire on management soft skills. The results revealed that the African migrants appear to be quite aware of the specific soft skills they owe to their cultural background, which ultimately might make them well equipped for better job opportunities when they actively apply them in their work environment. In continuance, this paper contrasts those findings with the results of a large European survey of migrants' soft skills conducted with companies' heads, personnel managers and business associations. Mirroring the results of both studies provides an insight into the extent in which the opinions on migrants' soft skills align and where they differ. This leads to infer that while migrants' skills enhance their ability to enter into the labor market, the skills also shape the market by creating niches for employment and this in turn changes how migrants deploy their skills.

There are various conclusions to be drawn: One is that integrating migrants into the labor market requires creative leadership and ethically founded decision-making: Both employers and employer associations must seek to fully utilize all the skills provided by the new entrants to the labor market. From a theoretical perspective, the two sets (of data but of interviewees as well) represent two distinct agglomerations of elements that are interrelated within each set, and they are also relating the sets to each other. This embeds a variety of systems-thinking constructs. Co-creation is one, and it regards to building a new set of information from not only the observations on skills offered and required but also from the developments that are triggered when offer and demand meet. One other is coalescing of equi-finality and multi-finality to arrive at a balance between needs of job-seekers and the job offers that can be satisfied short-term or for which long-term solutions are required. A third one is conjoining self-organization and relationality where skills development and labor market conditions enter into a systemic relation. For applying this concept, a parallel can be drawn to the innovation deployment projects that are run within the European Commission's Framework Programs (Kapsali, 2011). With regard to generating new opportunities in the job market, a systems-thinking interpretation would be that of an auto-poietic system (the development of skills) that interacts with the environment (the job market) and processes self-reference and other-reference. The paper evaluates the applicability of these concepts to the phenomenon of migrants in the labor market.

Keywords: migrants, soft skills, knowledge, labor market, systemic thought.

JEL Classification: J 24, J 20, J 11, A 13, Z 10.

(C) The Authors, 2017. This article is published with open access at ARMG Publishing. 


\section{Introduction}

When novel attitudes and behavior are found in people that enter the labor market or set up new businesses, their prospective employers or business partners face manifold challenges, one phenomenon in this regard comes from the cohorts of migrants entering societal and business environments which are new to them. This is most notable in Europe at present. Migrants bring diverse cultural backgrounds into the business environment. They are marked through differences in attitudes and behavior that produce diversities in soft skills which directly apply to the workplace. The differences include disposition towards networking, towards careers, towards the emphasis placed on training and development, and the need for meaningful work. Diversities of this kind can offer an added value for company competitiveness and, at the same time, they are a factor encouraging the employability of persons looking for a job. The whole representation has become of prime interest for policy makers, educators and human resource management.

The occurrences which originate from the new diversity in the labor market caused by migrants may in part be compared to the so called "millennials" who have as well added a new diversity in the business environment as they manifest attitudes in outlook, expectations, and work relationships which differ from the generations preceding it (Arsenault, 2004; Erickson, 2008; Meister and Willyerd, 2010; Shandler, 2009; Tapscott, 2009). Businesses have begun to appreciate that contributions from these younger and often well-educated workers are significant for organizational sustainability, that these employees are their real competitive advantage and that successful attraction and retention of this cohort of employees is a major management task (Todericiu, Şerban, and Dumitraşcu, 2013; Chartered Institute of Personnel Development, 2016; Thompson and Gregory, 2012). There is a clear parallel of this, though much less researched, in the addition to the labor force in developed countries of migrants with a background in less developed countries. This type of situation is becoming ever more significant in present-day Western Europe with most probably about 1.7 million migrants flowing in between the beginning of 2015 and the end of 2016. It has been said that these migrants will possibly influence the European labor market positively (Stirling, 2015); but conditions for accessing the European labor market e.g., during the processing of an asylum claim, vary significantly across countries. In some, labor market access can be granted, under specific conditions, almost immediately, whereas in others the waiting period can be as long as a year (OECD, 2105). In any case, the chances of integrating labor seekers into the sophisticated structures of, e.g., the German or the French labor market highly depends on their qualification.

With regard to "qualification", labor market statistics can employ the term for technical skills only, which is usually done by classifying into occupational categories based upon work performed, skills, education, training, and credentials in line with the International Standard Classification of Occupations of ILO (http://www.ilo.org/public/english/bureau/stat/isco/index.htm). There are attempts to also encompass soft skills if not into statistics so at least into surveys which could then serve to support policy making. For instance, the "Valorize High-Skilled Migrants (VHSM)" project which has been set up by Fondazione Casa di Carità, Italy, has conducted cross-country surveys on soft skills mostly required by companies to medium/high skilled migrants (Dall'Amico and Verona, 2015). In this project, the focus is on soft skills which enterprises generally consider as unavoidable for a successful participation in work and on the question if there are any soft skills which are specifically requested to immigrants wherever they come from. The VHSM surveys, consequently, approach relevant stakeholders such as enterprises, employment agencies, career centers, employers' associations. From there, VHSM aims at providing migrants with methods and tools to assess, develop and valorize their soft skills so as to empower them in job search. By contrast, the purpose of this paper is to approach migrants directly and to determine if their attitudes towards specific soft skills characteristics can be associated to their regional and cultural backgrounds, if these specific soft skills characteristics influence their chances in the labor markets and if the labor markets benefit from these skills.

The methodology of our paper is following the purpose laid out above: The assessment was conducted on soft skills with individuals (African professionals living in Germany) as opposed to companies. The individuals were either (a) born in a country other than their country of residence, which is Germany, or (b) possessed a nationality other than German, and/or (c) had changed their country of usual residence for a period of at least one year. The assessment was about which 'soft management skills' will most likely influence workplace conditions, both from their effect on business processes, value creation and stakeholder relations, as well as from their capacity to enable a smooth integration of migrants into the workforce. Thus, the assessment, albeit small, was to initially examine if and how migrants with a technical qualification (medium to high) are aware of their specific soft skills and if they subsequently apply them in their work environment. This outcome is subsequently compared with the insights from the study conducted with employers. This mirroring of data sets 
induces the question how the two entities - migrants offering special skills and employers offering jobs would come to terms. The answer can be found through applying systems thinking tools: The issue is about co-creating a balance between what the migrants and the job-providers offer, finding appropriate filters and variations that lead to mutual appreciation that allows for self-referencing and encourage the development of specific identities.

\section{The Nature of "Migrants" in Labor Market Research}

The status of foreigner varies from country to country, depending on local nationality law, which may be based on jus soli (the principle by which a country's nationality is acquired by birth in a country territorial jurisdiction), jus sanguinis (the principle by which a country's nationality is acquired through the nationality of the parents), or on a combination of the two (as it happens in most countries). There is not even a universally recognized statistical definition across the academic literature. The three following definitions are commonly used to define who is a migrant: (see Hawkins, 2015):

Someone born in a country other than his/her country of residence (this definition is objective, but it classifies as migrants individuals who are nationals of the country where they live, in spite of being born abroad (e.g. children born to expatriates)

$>$ Someone who has a nationality other than the one of the country where s/he lives (it excludes either nationals born abroad, or people having recently changed their country of residence and acquired the nationality of their new home country)

$>$ Someone who changes his or her country of usual residence for a period of at least one year, so that the country of destination effectively becomes the country of usual residence (this is the UN recommended definition; it is somewhat arbitrary as people's intentions regarding their length of stay in a country are subject to change).

Considering the above, the authors decided to use a broad-based definition of migrant within the present project, including either: a) people born in a country other than their current resident area, or b) people born in the country where they reside by newly nationalized immigrant parents.

For immigrants at the individual level, one imperative to succeed in the labor market is deemed that they adapt to the conditions of their host country, thus developing a sense of "national identity". Developing this sense of "national identity" is greatly affected by four interrelated factors: 1) the degree to which they are accepted by members of the host society; 2) immigrants' language skills and physical appearances; 3 ) how well they are able to balance their host national identity, their ethnic identity, and acceptance of their native country; and 4) their generational status (Luong, 2016).

The skills of migrants, the skills of existing workers, and the characteristics of the host economy are critical factors that impact the labor market in any country. Therefore, the effects of immigration and labor markets are a critical area of research with much of the research on this topic specific to time and place. For example, there are studies on the UK which looked into the wage effects of immigration and the impact on unemployment (Ruhs and Vargas-Silva, 2011). In this study, the researchers did not find a significant impact of overall immigration on unemployment in the UK, but the evidence suggests that immigration from outside the EU could have a negative impact on the employment of UK-born workers, especially during an economic downturn. Also, the evidence on the wage effects of immigration suggests that they are likely to be greatest for resident workers who are migrants themselves (Ruhs and Vargas-Silva, 2011: 1). Conversely, a study in Denmark for the period between 1991 and 1998 found that an increase in the supply of refugee-country immigrants pushed less educated native workers (especially the young and low-tenured ones) to pursue less manual-intensive occupations. As a result, immigration had positive effects on native unskilled wages, employment and occupational mobility (Foged and Peri, 2015). A number of UK studies suggest that at the micro level, i.e., for firms in local areas, migrants provide clear benefits. It has been found that migrants are important in filling skills gaps at all levels of the labor market, and in addition, are seen as having better 'soft' skills - in particular, punctuality, enthusiasm and a good work ethic (Institute of Employment Studies, 2006).

The skills effect also impacts on productivity (Raphael and Ronconi, 2007). For the U.S., a study of the National Bureau of Economic Research has explored the impact of immigration on total factor productivity, as well as on varied like average hours worked and physical capital accumulation. For this study, the researchers selected a state that is close to the Mexican border where the argument often is that immigrants crowd-out employment (take jobs away) and hours worked by locals (Peri, 2012). Although the study did not corroborate this argument, there was evidence that immigrant labor increased total factor productivity. As the 
capital-labor ratio remained constant, the effect on capital intensity, quite logically, was negative. From there, the U.S. study suggests that the productivity gains arose due to the efficient allocation of skills to tasks, as immigrants are allocated to manual-intensive jobs, promoting competition and pushing local or natives to perform communication-intensive tasks more efficiently (Peri, 2012: 351). This naturally leads to the question: what about the skills brought in by migrants who have a higher level of education, which may not be of a high number in the environment studied by the NBER research, but which certainly is occurring in present-day immigration to Europe (Adenekan-Koevoets, 2012)? In response to this, there is a parallel to earlier waves of immigration that came to (Western) Europe from Bulgaria and Romania after the fall of communism. In Denmark, for instance, a study reflecting the status of the year 2008 reveals that, while 68 percent of the natives have a post-secondary education, the percentage is 60 percent for refugee-country immigrants, which is surprisingly high (Foged an Peri, 2015: 7).

With relatively high educational levels and the willingness to succeed in their host countries, a question would be to what extent migrants preserve the cultural identity of their home countries. Casey and Dustmann (2010) have investigated how migrants living in Germany form an identity with home and host countries. One finding is that there is strong intergenerational transmission of identity from one generation to the next. However, the study found that identity with either country is only weakly related to labor market outcomes, like wages, labor market participation, employment and unemployment. But there is some evidence, according to the study, of a positive association between home country identity and employment, which the study explains with participation in ethnic networks that support labor market opportunities. The Casey-Dustmann study rather explores how identity is formed (and does not investigate which use migrants made of the characteristics embedded in this identity). Thus, it sets the focus on age, years since migration, gender, years of education, country of origin and arrival cohort in Germany, but it does not employ indicators on skills, neither technical nor non-technical.

Research on the effect of skills on labor market chances for migrants in Europe may be based on European labor market statistics that discern between low-skill and high skill migrants. Pertinent research (see, e.g., Collett and Zuleeg, 2008; Stirling, 2015) has shown that there is an employment gap for high-skill migrants: The difference between the employment rates of tertiary educated migrants and tertiary-educated non-migrants is larger than the gap existing between migrants and natives within any other qualification group. This finding may be due to the job characteristics used in the statistical system as it does not reveal self-employment. It also may show that the high-skill jobs market lacks inclusivity. But, in any case, the drawback of studies that use official statistics is that these statistics, as of yet, do not reveal any testimony of skills other than competencies related to vocational education and training.

Competencies related to vocational education and training have a direct link with the labor market as they describe skills and attitudes required for some tasks or responsibilities. It has been widely acknowledged, however, that both the labor market and the educational systems must define some 'key competencies useful for a successful life for individuals and a well-functioning society' (as per the title of a book by Rychen and Salganik, 2003), and the need to include both technical competencies ("hard skills") and social/personal competencies ("soft skills") has led to several UNESCO, OECD and European Union initiatives as will be set forth below.

\section{Soft Skills}

Skills, in general, are a "set of inborn and acquired personal characteristics, attitudes, knowledge and skills leading to high-quality performance" (European Framework, 2007). The soft skills framework used in U.S. and Latin American studies is known as the Big Five and includes the following broad categories and characteristics (Heckman and Kautz, 2012; Santos and Primi, 2014): Openness to New Experiences, Conscientiousness, Extraversion, Agreeableness and Emotional Stability. There are quite a few other definitions (Lepeley and Albornoz, 2012; Massaro et al., 2014), but any definition acknowledges that both soft and hard skills are descriptions of regular individual behavior (Robotham and Jubb, 1996). What is more important than a commonly accepted definition, though, is a common understanding to what are the elements that soft skills comprise, and, in the long run, an inclusion of these in surveys carried out by official entities, e.g., the national bureaus of statistics. An initial start to answer this was made in a report entitled 'Learning: the treasure within' by the International Commission on Education for the 21 st Century, set up by UNESCO and chaired by Jacques Delors. This document proposed four pillars of education: learning to know, learning to do, learning to live together, and learning to be (Delors, 1996). Another important step in the reflection on competencies was taken at the initiative of OECD with the 'DeSeCo' (Definition and Selection of 
Competencies) project (OECD 2001, 2005). The project classified key competencies in three broad categories: using tools interactively, interacting in heterogeneous groups and acting autonomously.

The evolution which comes most closely to a defining a set of skills that could be used in official statistics on issues of labor statistics is the European Framework of Key Competences adopted by the European Parliament in December 2006 after five years of work by experts and civil servants. It defines eight key competencies (European Framework, Annex p. L 394/13):

$>$ Communication in the mother tongue

$>$ Communication in a foreign language

$>$ Mathematical competence and basic competencies in science and technology

$>$ Digital competence

$>$ Learning to learn

$>$ Social and civic competence

$>$ Sense of initiative and entrepreneurship

$>$ Cultural awareness and expression.

At the same time, on the European level, the adoption of the Lisbon Agenda underlined the crucial importance of the acquisition of some key competencies for the well-being of citizens, which are social cohesion, strive for economic development, and efforts for competitiveness in the process of globalization (Halász and Michel, 2011). From this very wide range, let us narrow the focus on what may be gleaned on soft skills from management literature. A recent study involving one of the authors of this paper (Massaro, Bardy and Garlatti, 2015) has found that the importance of the "soft skills" concept has grown substantially in the management literature (See Figure 1 showing soft skills attributes found in the management literature between 1995 and 2013 - the fragmented line shows the number of articles per year in leading management journals and the regression line shows the trend).

There is an emphasis in the literature that soft skills determine employability. According to what was researched by Massaro, Garlatti and Bardy (2015) the main soft skills related to employability are: professionalism, reliability, ability to cope with uncertainty, ability to work under pressure, ability to plan and think strategically, capability to communicate and interact with others, written and verbal communication skills, information technology skills, creativity and self-confidence, self-management, and willingness to succeed (see Andrews and Higson, 2008: $413 \mathrm{f}$.). The list shown in Table 1 enumerates quantitative results of this literature review giving the number of papers that quote each of the soft skills ("Total") and which percentage of these papers define it as crucial ("\%").

Table 1. Main soft skills attributes found in leading management journals

\begin{tabular}{|l|c|c|}
\hline \multicolumn{1}{|c|}{ "Soft skills" } & Total & \% \\
\hline 1: Ideas Creation & 15 & $19 \%$ \\
\hline 2: Coordination ability & 8 & $26 \%$ \\
\hline 3: Multicultural ability & 20 & $10 \%$ \\
\hline 4: Planning ability & 8 & $14 \%$ \\
\hline 5: Learning ability & 11 & $9 \%$ \\
\hline 6: Professionalism & 7 & $16 \%$ \\
\hline 7: Leadership & 12 & $1 \%$ \\
\hline 8: Information management ability & 1 & $19 \%$ \\
\hline 9: Ethics & 15 & \multicolumn{2}{|c|}{$18 \%$} \\
\hline 10: Communication ability & 14 & $1 \%$ \\
\hline 11: Social responsibility & 5 & $1 \%$ \\
\hline 12: Entrepreneurship development & 1 & $3 \%$ \\
\hline 13: Collaborative governance & 1 & $14 \%$ \\
\hline 14: Sustainable Development & 2 & 2 \\
\hline 15: Dealing with others & 11 & \\
\hline
\end{tabular}

Source: Massaro, Garlatti and Bardy, p. 225.

Drawing from this list, the preceding study of the authors has tested if the importance of the skills attributed to them in the management literature would also be attributed by the persons responding to the survey. With this in mind, combined with: if people from different ethnic backgrounds would rank the importance differently, we would have an indication on what might determine their chances to get employed or to start a business of their own. Additionally, we would then ask: which skills they believe are best for their employability? This type of self-assessment would not only contribute to the respondents becoming aware of advantages (and, certainly, disadvantages) for coping with labor market and business environment challenges, 
but also a depiction of migrant-specific competencies, that would also promote adequate labor market policies and criteria for employee selection.

It is the proximity to management and business of the competencies as per the list of Table 1 which has motivated the authors to choose these items for the survey they conducted with two groups of immigrants in two diverse economic environments. In this, our approach that will be explicated more closely in the Methodology section is deviating from other studies. These other studies (e.g. Hilbert and Schömann 2004, Wye and Lim 2009) use a criterion that distinguishes between personal attributes and attitudes (confidence, discipline, self-management...), social competencies (communication, team working, emotional intelligence.) and managing abilities (time keeping, problem solving, critical thinking) as per the Cedefop Glossary (http://euskillspanorama.cedefop. europa.eu/Glossary/). Cedefop is the Centre Européen pour le Développement de la Formation Professionnelle (European Center for the Development of Vocational training), a EU agency headquartered in Thessaloniki, Greece. The agency works for policy makers and practitioners of the European Commission, the EU Member States and employer as well as employee associations. By nature, the definition used here need to be rather general.

\section{Methodology and results of the survey on the group of African migrants}

For the purposes of the survey, an online questionnaire was developed which uses the findings of the Massaro, Garlatti and Bardy (2015) study as well as the principal structure of the VHSM cross-country survey on migrants with medium to high technical skills in Europe, (Dall'Amico and Verona, 2015). Procedurally, African professionals living in Germany received emails by the respective directors of their affiliated organizations and were asked to complete the online survey. The email provided link to the survey and briefly explained that the purpose of this initial study was to pilot the survey instrument with individuals and to conduct preliminary investigation into their attitude and perception towards "soft management skills". Approximately three weeks after the initial email, a second email was sent out.

The online survey instrument provided an introduction to taking the survey, the purpose of the survey, and an initial consent (students were instructed to click on taking the survey if they agreed). It was divided into five sections.

Section one: Section one asked the respondents to rank order the 'top five soft skills concepts' from a list of 15 concepts related to soft skills as reported in business literature and practice:

\begin{tabular}{|ll|l|l|}
\hline $1 . \quad$ idea creation & 6. learning ability & 11. information management ability \\
\hline 2. $\quad$ coordination ability & 7. professionalism & 12. entrepreneurship development \\
\hline $3 . \quad$ multicultural ability & 8. leadership & 13. collaborative governance \\
\hline $4 . \quad$ planning ability & 9. ethics & 14. sustainable development \\
\hline 5. $\quad$ communication ability & 10. social responsibility & 15. dealing with others \\
\hline
\end{tabular}

Section two: Section two of the survey was divided into three sub-sections: a) Navigating the Work Environment; b) Social Skills; and c) Achieving Results. In this section, the interviewees were asked to rate the level of importance (from not important to extremely important) that companies assign to soft skills. Second, they were asked: the level of 'difficulty' to develop the skills (Is it difficult to develop these skills yes, no, don't know). Below are the three sub-sections to Section two of the survey:

\section{A. Navigate the Work Environment}

Identifying work goals:

Ability to take decision about how, when, where to work, developing personal insights into goals.

Learning to learn:

$>$ Attitude to curiosity (questioning, looking for information);

$>$ Attitude to pursue one's own learning according to one's needs (responsibility for one's own selfdevelopment);

$>$ Attitude to be aware of opportunities.

Adaptability and flexibility:

$>$ Capacity to accept changes as a new challenge;

$>$ Capacity to adapt to new situations and modify approaches if required by the context.

\section{Motivation:}

$>$ Attitude to be energetic and enthusiastic and capacity to self-motivate and motivate.

Recognizing/ applying work protocols and values:

$>$ Ability to recognize and apply company values, culture and etiquette; 
Ability to adapt/act in accordance to places and situations (properly dressed, accepting customs of the work environment, etc.).

Respecting hierarchical levels and rules:

$>$ Capacity to understand/recognize the organization policies and structure;

- Capacity to take responsibility for one's own actions without blaming anyone else for something s/he is liable for.

Time management:

$>$ Capacity to respect schedule and deadlines and being on time.

Managing the digital process (not related to the use of software and office automation):

$>$ Capacity to get information using digital systems \& technology;

Capacity to work with Netiquette;

Capacity to manage risks associated with on line environments.

B. Social Skills

Communication skills:

$>$ Capacity to speak clearly and politely to any typology of speakers (heads, colleagues, clients, etc.);

$>$ Capacity to use body language, gesture, tone/pitch of voices properly at different levels and contexts;

$>$ Capacity to know what medium to use when communicating at different level and contexts.

Managing the communication circle:

$>$ Ability in active listening, repeating, recollecting, interpreting (paraphrasing), empathy (being aware of others' feelings), giving feed-back

Personal effectiveness and integrity

$>$ Capacity to maintain good level of performance when dealing with environmental pressures and difficulties (self-control, resilience, self-confidence)

Team working:

$>$ Capacity to adapt to new situations and modify approaches if required by the context;

$>$ Service skills (understanding of others' needs);

$>$ Capacity to offer support to others when asked for;

> Capacity to Identify and respond to client needs and dial politely with clients problems (customer orientation).

Service skills (understanding of other needs):

$>$ Capacity to offer support to others when asked for;

$>$ Capacity to Identify and respond to client needs and dial politely with clients problems (customer orientation).

C. Achieving Results

Leadership:

$>$ Capacity to lead her/himself first;

> Capacity to lead groups of people and make them work for a common goal;

$>$ Capacity to inspire/influence on others producing an impact;

$>$ Capacity to give and receive feedback on good/poor performance;

Capacity to delegate to direct subordinates in the team.

Conflict management:

$>$ Ability to detect a conflict at an early stage without being afraid of calling it "conflict";

> Ability to manage conflict when it arises and understand which conflicts cannot be solved;

Ability to mediate, acting in such a way that ones' and other's goals will be achieved (win-win approach).

Cross-cultural awareness:

$>$ Capacity to recognize and use diverse perspectives according to different values, beliefs and behaviors of different cultures, by demonstrating respect;

D Capacity to take appropriate actions to minimize cultural, gender or other diversity difficulties, actual or perceived.

Decision making:

$>$ Capacity to make a choice from a range of possibilities (also prioritizing actions) and use different decisionmaking approaches. 


\section{Problem solving:}

$>$ Capacity to find and solve routine and non-routine problems to achieve work goals, as well as to anticipate them and reflect on the outcomes.

\section{Creativity and innovation:}

> Ability to come up with new solutions, approaches, etc., and to think "out of the box".

Critical and structured thinking:

$>$ Ability to analyze and valorize information and accept constructive criticism.

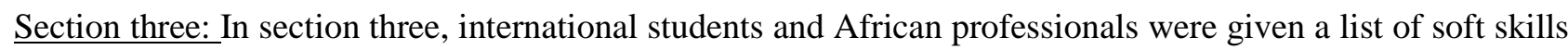
and were asked to mark (based on their experience and perception) which soft skills they are 'lacking' and that might have the 'greatest negative impact' on their business performance. Below is the list of soft skills that was given:

\begin{tabular}{|c|c|c|c|c|}
\hline $\begin{array}{l}\text { Identifying work } \\
\text { goals }\end{array}$ & $\begin{array}{l}\text { Managing the digital } \\
\text { process }\end{array}$ & Decision making & Problem solving & Team working \\
\hline Time management & $\begin{array}{l}\text { Cross-cultural } \\
\text { awareness }\end{array}$ & Motivation & $\begin{array}{l}\text { Personal effectiveness } \\
\text { and integrity }\end{array}$ & $\begin{array}{l}\begin{array}{l}\text { Critical and structured } \\
\text { thinking }\end{array} \\
\end{array}$ \\
\hline $\begin{array}{l}\text { Conflict } \\
\text { management }\end{array}$ & $\begin{array}{l}\text { Adaptability and } \\
\text { flexibility }\end{array}$ & $\begin{array}{l}\text { Managing the } \\
\text { communication circle }\end{array}$ & $\begin{array}{ll}\text { Creativity } & \text { and } \\
\text { innovation } & \end{array}$ & $\begin{array}{l}\text { Service skills (understanding } \\
\text { of others' needs) }\end{array}$ \\
\hline Learning to learn & Communication skills & $\begin{array}{l}\text { Recognizing/ applying } \\
\text { work protocols }\end{array}$ & $\begin{array}{l}\text { Respecting hierarchical } \\
\text { levels and rules }\end{array}$ & Managing responsibilities \\
\hline Leadership & Values & & & \\
\hline
\end{tabular}

Section four: In section four, a list of 'business tasks' was given where soft skills are considered extremely important for high-skilled workers. In this section the African professionals were asked to 'mark 3 choices' (based on their experience and perceptions) from the list of business tasks where Soft Skills are considered extremely important for high-skilled workforce. The following list shows which business tasks were given:

\begin{tabular}{|l|l|l|}
\hline \multicolumn{1}{|c|}{ Management } & \multicolumn{1}{c|}{ General Services (i.e. maintenance) } & Administration - Accountancy - Finance \\
\hline Customer Services & Personal care service & IT \\
\hline R\&D & Communication-P.R. & Logistics and Quality \\
\hline Human Resources - Training & Import/export & Marketing \& Sales \\
\hline Production & & \\
\hline
\end{tabular}

Directly following this section, a 'General Comment' section was provided, where respondents could give their general comments on the survey could be given. Finally, in a 'Demographic Section' the respondents were asked a variety of demographic questions related to their background, and employment/business status.

All of the participants' responses were stored within the survey system (Checkbox Survey Software). At the conclusion of the survey period, all data was downloaded into Microsoft Excel@ for survey analysis.

The pilot testing of the online survey had only 14 respondents because the questionnaire was obviously deemed to be heavily loaded. However, the authors considered this load to be necessary as would produce a data set that corresponds to the results of the VHSM study. Most of the participants listed their age bracket as 23-30 years old (86\%), and over half of the respondents $(57 \%)$ said they were students with half of them attending university or technical school full time. The others had Bachelor (43\%) or Masters (36\%) degrees. Most of the participants from African background were born in Germany (71\%), however, many stated that their parents migrated from various parts of Africa (Eritrea, Congo, Nigeria, and Sierra Leone).

The participants ranked the below listed skills as most important from the list of skills companies look for in high-skilled workforce:

> Capacity to adapt to new situations and modify approaches if required by the context;

$>$ Time management and the capacity to respect schedule and deadlines and being on time;

$>$ Capacity to maintain good level of performance when dealing with environmental pressures and difficulties (self-control, resilience, self-confidence);

$>$ Conflict management and the ability to detect a conflict at an early stage without being afraid of calling it conflict;

$>$ Capacity to make choice from a range of possibilities (also prioritizing actions) and use different decisionmaking approaches; and

A Ability to analyze and valorize information and accept constructive criticism.

They also added the following as important or extremely important skills that companies should look for in high-skilled workforce: 
Honesty, friendliness, and passion;

Identification of work goals;

Creativity and Innovation;

Conflict Management;

Team Work

Leadership.

Section three of the survey asked the participants (based on their experience and perception), which soft skills that they might lack might have the greatest negative impact on business performance. The highest reported skills were: motivation and time management. This sharply contrasts with the outcome of a test-query submitted to U.S. international students at Florida Gulf Coast University which is column of Table 2 below. The comparison clearly marks that there is a definite specifity in the assessments of African migrants.

Table 2. Soft Skills with Greatest Impact on Business Performance

\begin{tabular}{|l|c|c|c|c|}
\multicolumn{5}{c}{ U.S. Int. Students } \\
\hline \multicolumn{1}{|c|}{ Soft Skills } & No. & Percent & No. & Percent \\
\hline Identifying work goals & 10 & $9.90 \%$ & 2 & $2.60 \%$ \\
\hline Learning to learn & 2 & $1.98 \%$ & 2 & $2.60 \%$ \\
\hline Adaptability and flexibility & 6 & $5.94 \%$ & 3 & $3.90 \%$ \\
\hline Motivation & 4 & $3.96 \%$ & 7 & $9.09 \%$ \\
\hline Recognizing/ applying work protocols & 1 & $0.99 \%$ & 1 & $1.30 \%$ \\
\hline Values & 2 & $1.98 \%$ & 1 & $1.30 \%$ \\
\hline Respecting hierarchical levels and rules & 4 & $3.96 \%$ & 4 & $5.19 \%$ \\
\hline Managing responsibilities & 9 & $8.91 \%$ & 7 & $9.09 \%$ \\
\hline Time management & 8 & $7.92 \%$ & 6 & $7.79 \%$ \\
\hline Managing the digital process & 2 & $1.98 \%$ & 3 & $3.90 \%$ \\
\hline Communication skills & 8 & $7.92 \%$ & 4 & $5.19 \%$ \\
\hline Managing the communication circle & 2 & $1.98 \%$ & 6 & $7.79 \%$ \\
\hline Personal effectiveness and integrity & 1 & $0.99 \%$ & 3 & $3.90 \%$ \\
\hline Team working & 9 & $8.91 \%$ & 5 & $6.49 \%$ \\
\hline $\begin{array}{l}\text { Service skills (understanding of others } \\
\text { needs) }\end{array}$ & 1 & $0.99 \%$ & 6 & $7.79 \%$ \\
\hline Leadership & 10 & $9.90 \%$ & 1 & $1.30 \%$ \\
\hline Conflict management & 2 & $1.98 \%$ & 5 & $6.49 \%$ \\
\hline Cross-cultural awareness & 2 & $1.98 \%$ & 5 & $6.49 \%$ \\
\hline Decision making & 5 & $4.95 \%$ & 3 & $3.90 \%$ \\
\hline Problem solving & 4 & $3.96 \%$ & 3 & $3.90 \%$ \\
\hline Creativity and innovation & 5 & $4.95 \%$ & 5 & $4.95 \%$ \\
\hline Critical and structured thinking & 4 & $3.96 \%$ & 4 & $3.96 \%$ \\
\hline
\end{tabular}

Similarly, a test query was conducted with U.S. international students on that part of the survey which asked in which business tasks Soft Skills are considered extremely important. Both group ranked 'management' highly, but 'marketing and sales' were considered much more important by the Africans (see Table 3 below).

Table 3. Main Business Tasks Where Soft Skills are Extremely Important

U.S. Int. Students

\begin{tabular}{|l|c|c|c|c|}
\multicolumn{2}{c}{ U.S. Int. Students } & Count & Percent \\
\hline \multicolumn{1}{|c|}{ Main Business Tasks } & Count & Percent & 11 & $28.95 \%$ \\
\hline Management & 9 & $25.00 \%$ & 2 & $5.26 \%$ \\
\hline $\begin{array}{l}\text { Administration - Accountancy } \\
\text { Finance }\end{array}$ & 3 & $8.33 \%$ & 6 & $15.79 \%$ \\
\hline Communication - P.R. & 4 & $11.11 \%$ & 5 & $13.16 \%$ \\
\hline Human Resources - Training & 5 & $13.89 \%$ & 6 & $15.79 \%$ \\
\hline Marketing \& sales & 1 & $2.78 \%$ & 1 & $2.63 \%$ \\
\hline Customer Services & 5 & $13.89 \%$ & 1 & $2.63 \%$ \\
\hline R\&D & 2 & $5.56 \%$ & 1 & $2.63 \%$ \\
\hline IT & 1 & $2.78 \%$ & 1 & $2.63 \%$ \\
\hline Import/export & 1 & $2.78 \%$ & 1 & $2.63 \%$ \\
\hline Production & 1 & $2.78 \%$ & 2 & $5.26 \%$ \\
\hline Personal care service & 1 & $2.78 \%$ & 1 & $2.63 \%$ \\
\hline Other & 3 & $8.33 \%$ & & \\
\hline
\end{tabular}

Surveying a set of only a small sample is certainly not sufficient for drawing conclusions that would apply to a wider scope or generalizability for articulating policy recommendations. However, it is the opinion of the authors that the survey instrument can provide fertile ground for future research into migrants' attitudes and 
opinions towards management soft skills. This is said for several reasons. For one, there are distinct variations in the comparison with the U.S. international student group which confirms the influence on skills of an ethnic background, and secondly, the self-assessments show a clear reflection from the African group on how their specific soft skills could be applied to its advantage. From there, the point may be raised that cohesion of an ethnic group works to its benefit.

One of the factors that comprise ethnicity is personal ties, such as friendship networks or ethnic associations. Belonging to a group not only facilitates community building, it also strengthens the awareness of specific characteristics. There are a number of factors internal to ethnic categories which facilitate their transformation into viable social groups. These factors include (1) common culture or customs (i.e., cultural homogeneity); (2) a sense of peoplehood (i.e., ethnic identity); (3) leadership; (4) institutions; (5) informal relations such as friendships; and (6) "race" (Driedger, 1989:143). Earlier research found that ethnic minority networks promote employability and wage levels (Åslund, Östh and Zenou, 2010; and Damm, 2009), and there is some evidence for diaspora networks and referral networks based on ethnicity (Kuznetsov and Sabel, 2006; Mason, 2009; Dustmann, Glitz and Schoenberg, 2009). The research does not specify if these networks' effects arise from specific skills characteristics of the ethnic groups, but it recognizes that their positive effect on employment is not just due to the acquisition of the host country's language which these networks often encourage (Dustmann, Glitz and Schoenberg, 2009: 34). So, it is most likely that the effects come from the cohesion of the groups and their awareness of possessing distinctive cultural skills.

Distinctive cultural skills are a characteristic of Africans, and one short insight on these characteristics shall be made here. African tradition has long-standing means of bottom-up decision making and concocting common ideas. In Botswana, for example, the 'Kgotla' is the central decision-making agency of a village and serves as the village's administrative and judicial centre. It is presided over by the local chief, and all adult community members are expected to attend to discuss public affairs (Silitshena, 1992). The Zulu and Xhosa as well as the Swazi use 'Indaba' or 'Indzaba' to make people get together to sort out the problems that affect them all, where everyone has a voice and where there is an attempt to find a common mind. The word, in their languages, means 'business' or 'matter' (Newenham-Kahindi, 2009). Another concept is Kanju, a term that describes a specific creativity born from African difficulty. Kanju is "the rule-bending ethos that makes it possible to get things done in the face of headaches like crumbling infrastructure, corrupt bureaucracy and tightfisted banks unwilling to make loans to people without political connections" (Olopade 2015: 20 ff.). One other principle by the name of Ubuntu in Zimbabwean, and Hunhu/Kuntu/Munhu in other African languages, is "the ability to overpowering urges in one's own physical being" (Chivaura 2007: 232). Its emphasis is on coexistence, built on harmony, peace and justice - the "African way of how to connect with people" (Newenham-Kahindi 2009: 90).

Our findings suggest that the African immigrants to Germany relate the distinctiveness of their workplace skills to the beliefs and values of their origin countries. And this identity is obviously transferred from one generation to the next. That is commensurate with an outcome of the analyses by Casey and Dustmann (2010 who found that there is a strong and significant association between parents' and children's home and host country identities, and that there is indeed a transmission of the home country identity (Casey and Dustmann, 2010: F 22). Now, what do we perceive in this regard from the U.S. sample, where a majority of the survey participants has a Latin American background?

In all, the survey demonstrates that high skilled individuals with a migratory background are disposed to make use of their competencies, be it within the cognizance of group specificity, like the African professionals interviewed in Germany, or in a more acculturated fashion like the international students who responded to the survey at a U.S. university. This deployment of competencies comes clearly forward in the answers given to the questions regarding the main business tasks where soft skills are extremely important (Table 3). But there is a difference, again, as the importance attributed to communication / public relations and marketing / sales is higher from the African group than from the U.S. international students - another evidence of diversity in the perspective on how to connect with people for which Africans have their long-standing endogenous approaches as mentioned above. 


\section{Comparing the migrants' responses with the results of the VHSM survey}

As referred to above, the survey conducted in the VHSM project was addressed to labor agencies and employers. It asked about soft skills of migrants, but it did not delve into the specific nature of soft skills in the same way as the survey that was conducted with migrants. Nevertheless, and even though no one of the corporate interviewees specified any soft skills required specifically to high-skilled migrants (Dall'Amico and Verona 2015, p 41), soft skills were mentioned to be an important factor which may positively influence immigrants' job insertion as per Table 4 .

Table 4. "Pull factors" for inserting migrants into a company's labor force

\begin{tabular}{|l|l|}
\hline \multicolumn{2}{|c|}{ Factors which may positively influence the decision to hire an immigrant } \\
\hline Multi-language knowledge & Mastery of their mother language and language of the resident country \\
\hline Cross-cultural competences & $\begin{array}{l}\text { Ability to manage intercultural understanding and communication, awareness and sensitivity } \\
\text { of other practices and cultures, which immigrants learn going through their life experiences }\end{array}$ \\
\hline Geographical mobility & Immigrants are generally more inclined to move from a place to another one for job reasons \\
\hline $\begin{array}{l}\text { Image of immigrants } \\
\text { socially spread and } \\
\text { shared by local culture }\end{array}$ & $\begin{array}{l}\text { As an example, Egyptians are considered as excellent in the building sector because of their } \\
\text { long-lasting migration experience in the Gulf countries where they are mostly employed in this } \\
\text { economic sector; Romanians are well known for their dynamism } \\
\text { and entrepreneurship attitude, etc. }\end{array}$ \\
\hline Education level & It is often higher than the tasks they are effectively assigned to \\
\hline Technical and professional skills & $\begin{array}{l}\text { It is a strong strength when it refers to an economic sector or professional where there is a } \\
\text { shortage of manpower }\end{array}$ \\
\hline
\end{tabular}

Source: Dall'Amico and Verona 2015, p 41.

On a more detailed level, the following answers were given by the employers about which skills are deemed lacking or must be improved in their companies' current workforce from which one may glean that migrants which enter this workforce will have to be even more equipped in this regard:

1. Time Management (47\% of the respondees placed this on the highest rank);

2. Creativity/Innovation (47\%);

3. Team Working $(46 \%)$;

4. Adaptability and Flexibility (39\%);

5. Problem Solving (39\%);

6. Motivation (38\%);

7. Conflict Management (36\%);

8. Critical and Structured Thinking (36\%).

The interviewees' perception changes if they are asked which skills, if lacking, may have the greatest negative impact on their company. In this case list is:

1. Motivation (56\%);

2. Problem Solving (55\%);

3. Time Management, Team Working Conflict Management, Communication Skills, Creativity/ Innovation (ex aequo 44\%);

4. Adaptability and Flexibility (43\%);

5. Identifying Work Goals (40\%).

There is a marked difference in this ranking to those of the surveys conducted with the migrants. Since the group of Latin migrants to America served as a reference only, significant conclusions are mainly to be drawn from the differences observed between the statements of European employers and their prospective employees - i.e. the African migrants in Germany. This will be analysed in the next section.

Conjoining the two data sets to conjecture on consequences for the labor market through systemsthinking frameworks

When viewing how the perceptions differ with regard to which soft skills are the most important ones for the workplace, conjectures can be drawn on the need for policy measures. This would especially apply to the African migrants in Germany, because it is the European employers whose opinions seem to starkly diverge from those of their prospective employees. This is shown in Table 5, which also contains the responses from the group of Latin migrants to America, which serves as a reference. 
Table 5. Comparative Ranking of Soft Skills with Greatest Impact on Business Performance

\begin{tabular}{|c|c|c|c|}
\hline & $\begin{array}{l}\text { U.S. Int. } \\
\text { Students }\end{array}$ & $\begin{array}{c}\text { Africans } \\
\text { in Germany }\end{array}$ & $\begin{array}{r}\text { European } \\
\text { Employers }\end{array}$ \\
\hline Soft Skills & Rank No. & Rank No. & Rank No. \\
\hline Identifying work goals & 10 & 2 & 5 \\
\hline Learning to learn & 2 & 2 & 6 \\
\hline Adaptability and flexibility & 6 & 3 & 8 \\
\hline Motivation & 4 & 7 & 7 \\
\hline Recognizing/ applying work protocols & 1 & 1 & 5 \\
\hline Values & 2 & 1 & n.a. \\
\hline Respecting hierarchical levels and rules & 4 & 4 & 4 \\
\hline Managing responsibilities & 9 & 7 & 7 \\
\hline Time management & 8 & 6 & 10 \\
\hline Managing the digital process & 2 & 3 & 3 \\
\hline Communication skills & 8 & 4 & 7 \\
\hline Managing the communication circle & 2 & 6 & 6 \\
\hline Personal effectiveness and integrity & 1 & 3 & 6 \\
\hline Team working & 9 & 5 & 9 \\
\hline Service skills (understanding of others' needs) & 1 & 6 & n.a. \\
\hline Leadership & 10 & 1 & 4 \\
\hline Conflict management & 2 & 5 & 6 \\
\hline Cross-cultural awareness & 2 & 5 & 4 \\
\hline Decision making & 5 & 3 & 6 \\
\hline Problem solving & 4 & 3 & 8 \\
\hline Creativity and innovation & 5 & 5 & 10 \\
\hline Critical and structured thinking & 4 & 4 & 6 \\
\hline
\end{tabular}

Source: Authors, and from Dall' Amico and Verona 2015.

The divergences exhibited in Table 5 are one manifestation of the phenomenon that job requirements and job skills provided by job seekers can never be ideally matched. But while this mismatch, when it relates to hard skills, can mostly be remedied through learning or through assigning a job where the match is more appropriate, the background of divergences in job-seekers' and employers' views on the applicability of soft skills is more complicated. When soft skills originate in ethnic specifity, they must be seen as cultural markers which have a systemic relation to the shared meanings attributed to attitudes and beliefs. Any satisfactory discussion of how to solve those divergences must involve a deep understanding of the relevant culture from both parties' perspectives. One substantial disparity lies with social cohesion which is a "primordial attachment", i.e. how a person "is bound to one's kinsman, one's neighbor, one's fellow believer" ... "as the result not merely of personal affection, practical necessity, common interest, or incurred obligation, but at least in great part by virtue of some unaccountable absolute import attributed to the very tie itself" as per the seminal contribution of Geertz (1973: 259 - 60). Geertz's view on the issue become very up-to-date in today's labor markets where such attachments are possessors of certain especially significant relational qualities (Larin, 2010). One clear example is how the Africans in Germany, as surveyed by our study, differ from European employers in their attitude towards most of the issues depicted in the listings of Table 5.

One approach to bridge the gap may be a prudent policy of integration. "Prudency" would mean that cultural misunderstandings and communication failures have to be carefully avoided, and it is therefore important that cultural diversity training is provided for all employees, not just the migrants, particularly at management and supervisory level (see, e.g., Williams Prendergast, 2009, about the pertinent policies in Ireland; Bager and Rezaei, 2001, on the risk of capturing immigrants in marginal business fields in Denmark; Gunasekara, Rajendran and Grant, 2015, on whether Sri Lankan and Indian skilled migrants are satisfied with their jobs in Australia). But foreignness is not a liability at all times: Immigrants have set up shops almost anywhere in urban Europe. From Pakistani owned Indian restaurants in Trondheim to Chinese leather firms in Milan and from Turkish butcher shops in Berlin to Caribbean tobacconists in Liverpool: immigrant entrepreneurs have successfully exploited opportunities for small businesses in many cities (cf. Kloosterman and Rath, 2003). So "integration" may be the wrong denominator; a different approach would be characterized by policies that embrace the lemma of "Listen to me, Learn with me" (Williams, 2007).

The plea to 'listen to me, learn with me' gives rise to a number of policy implications. First, it questions the effectiveness (quite apart from the equity) of national immigration regimes, and the extent to which these support national innovation systems. Most such schemes revolve around provisions for 'skilled' or 'highly skilled' workers; they singularly fail to recognize the different types of personal knowledge possessed by other 
knowledgeable workers. Secondly, even after knowledgeable workers manage to hurdle the barriers posed by immigration and employment laws, there are still considerable obstacles at company level, and it is only the most progressive firms which recognize the knowledge premium of social diversity (Williams, 2007: 34-5). This is one of the aspects that connect to systems thinking: Dealing with social diversity is a two-ways-path, and it needs a framework that systemically intertwines the elements that contribute to an effective outcome of 'listen to me, learn with me'. Our two sets of rankings represent two distinct agglomerations of elements that are interrelated within each set, and they are also relating the sets to each other. If employers and migrants wish to arrive at a mutual comprehension, the systems thinking construct of co-creation may pose a way to building a new insight not only on why skills offered and required differ but also on the developments that are triggered when those differences collide in the labor market. If we just take one example: While both groups give an equal rank to "Respecting hierarchical levels and rules", the migrants rank "Team working" with 5 on a scale from to 10 while the employers rank it at level 9. But since we know that Indaba and Kgotla are widely dispersed instruments of collective decision making in African societies (see above), there must be a misunderstanding of what is meant by "team" which could be bridged by clearly defining the rights and responsibilities of a team leader. What needs to be aspired here is to mediate between the social contexts which generate the difference in attitudes: the mediation consists in the application of competencies of people eventually leading to an act of co-creation (Franz, Hochgerner and Howaldt, 2012).

The term "Co-Creation" is mostly used with regard to businesses and their customers sharing their knowledge to define which characteristics and qualities are needed for a new product (see, e.g., Espejo and Dominici, 2017). But there is also an application of the concept in social innovation literature that regards the bridging of "mutual ignorance" across social boundaries. Barraket and Furneaux, drawing on Mulgan et al. (2007) integrate organizational, sectoral and disciplinary clusters of knowledge and arrive at compelling new relationships, thereby stimulating a dialogue between social innovation studies and service innovation studies. Integration, here, is meant to be an iterative process that involves reflection among stakeholders, within the three stages of co-design, co-production and co-dissemination (Antonacopoulou, 2009).

Another systems-thinking device that can address the phenomenon of diverse views on the importance of soft skills is coalescing of equi-finality and multi-finality: In order to arrive at a balance between needs of jobseekers and the job offers that can be satisfied short-term or long-term, we need to explore into the finality of skills. If, for example, "Identifying work goals" ranks higher from the employers' viewpoint, we need to clarify to the migrants which goal is sought with this. Similarly, the difference in viewing at the importance of "Creativity and innovation" may be bridged by clarifying that there are various, sometimes conflicting, goals in providing an environment where everyone may pursue his or her own new ideas: one may be to exploit all intellect that is available in order to just arrive at an inventory of what ideas exist, another one may be to purposefully channel the diverse ideas to a common objective. Either way will foster innovation. The junction of equi-finality (the overall objective of improving the workplace), multi-finality (the diverse goals of job offerors and job seekers), feedback, self-organization (of the actors) and relationality (see Jackson, 2003) creates an atmosphere of both accountability and trust is a primordial facet in the workplace community.

Generally, from a Luhmannian perspective (Maturana and Varela, 1980), the migrant community can be understood as a system that was originally affected by the lack of chances to properly maintain sustainability in its societal environment but whose members are now seeing an opportunity to gain new chances from interacting with members of another system, which is the labor market (see also Valentinov, 2015). This connects to a third device of systems-thinking which is conjoining self-organization and relationality: Skills development and labor market conditions need to enter into a systemic relation. Many of the soft skills that are listed in Table 5 are dependent on each other, and the same goes for the requirements that are found in the labor market. We may view them as two clusters whose elements will develop into a state of self-organization if they interact. They are an open-system, where all of its components (actors, organizations and skills) are open to each other's influence because they interact and relate through their boundaries (Rametsteiner and Weiss, 2006).

For applying the concept of conjoining self-organization and relationality, a parallel can be drawn to the innovation deployment projects that are run within the European Commission's Framework Programs (Kapsali, 2011). With regard to the job market, new evolvements will come up without outside intervention just from the interplay between what is offered and what is needed: A systems-thinking interpretation would be that of an auto-poietic system (the development of skills) that interacts with the environment (the job market) and processes self-reference and other-reference, i.e. towards the additional determinants of job creation. Migrant learning and learning from migrants, including the respective knowledge creation/transfer, 
must become a widely dispersed practice. It has long been argued that the cohabitation of very tightly bounded work and social spaces ensures the exchange of knowledge, a feature that has also been noted to achieve astonishing results, e.g. in the service industry (Williams and Baláž, 2014). We can also find this in our list of rankings: The African migrants rank "Decision making" and "Problem solving" relatively low which might be a sign of reverence to the abilities of people in higher hierarchical levels. But, over time, when given the opportunity to make decisions on their own, self-organization of these two concepts will grow and mature into developing leadership abilities. Effectiveness in the labor market is always achieved only if interpersonal interactions are properly handled - and if interactions with migrants are properly handled, the labor market will benefit greatly.

\section{Conclusion}

We have presented an inter-group comparison which aims to demonstrate that the cultural backgrounds of migrants shape their social abilities and competencies and that a mindful usage of these soft skills may improve their chances in a foreign labor market. Confronting highly educated Africans residing in Germany with an online questionnaire which is identical to what was surveyed with European employers achieved a set of answers which supports the assumption of this cultural impact. The participation in the online questionnaire was rather small, and thus the result may not be sufficient for generalizability, but the outcome still shows that this survey instrument can be used to assess management soft skills as it clearly discriminates the following. First, there are distinct features in a group of people that have a similar ethnical background, which confirms the influence on skills of specific culture. Second, with the African group's answers differing substantially the answers given by the employers, the need is verified for migrants to learn more about what soft skills are deemed important by those who offer jobs - as well as the need for employers to learn why specific features are ranked differently by the migrants. And, thirdly, as the self-assessments show a clear reflection from the African group on how their specific soft skills could be applied to its advantage, the point may be raised that cohesion of an ethnic group works to its benefit. From this initial data analysis, subsequent studies would considerably contribute to stimulating future research into migrants' attitudes and opinions towards management soft skills and the consequences for labor markets.

The study also points towards a responsibility of employers and employer associations to act prudently, deploying both leadership and an ethical foundation when deciding about job-characteristics and job creation. It does not suffice to demand that foreigners need to adapt to a host country's social systems (which they certainly must), but those who represent those social systems need to deploy a deep understanding of the circumstances and the background of migration and of what migrants may offer to a labor market. They need to have a second look - beyond what just surfaces from an employment seeker's documents, right into the cultural specifities that shape a person.

On the theoretical end, the relations between the two clusters of perspectives on soft skills are clearly serviceable for systems-thinking: Co-creation, coalescing of equi-finality and multi-finality and conjoining self-organization and relationality are noticeably applicable to the phenomenon of skills offer and skills requirement when jobs are becoming available not only for migrants but also for other new segments of the labor force. It is hoped that this study promotes the deployment of these and perhaps other systems-thinking devices to issues found in the labor market.

\section{References}

1. Adenekan-Koevoets, B. (2012). Human Capital of Immigrants. Master Thesis Human Geography, Radboud University Nijmegen, Netherlands.

2. Alisic, E. and Letschert, R.M. (2016). Fresh eyes on the European refugee crisis. European Journal of Psychotraumatology, 7(10). Published online 2016 May 12. doi: 10.3402/ejpt.v7.31847.

3. Andrews, Jane and Higson, Helen (2008). "Graduate employability,'soft skills' versus 'hard'business knowledge: A European study”. Higher education in Europe 33.4, 411-422.

4. Antonacopoulou, E.P. (2009). Impact and scholarship: unlearning and practicing to co-create actionable knowledge. Manage Learn, 40, 421-430.

5. Arsenault, P. M. (2004). Validating generational differences: A legitimate diversity and leadership issue. The Leadership \& Organization Development Journal, 25(2), 124-141.

6. Åslund, Olof, John, Östh and Yves, Zenou (2010). "How important is access to jobs? Old questionimproved answer". Journal of Economic Geography 10.3, 389-422.

7. Bager, T., and Rezaei, S. (2001). Immigrant Business in Denmark: Captured in Marginal Business Fields? Working Paper 2001/1, Centre for Small Business Studies, University of Southern Denmark. 
8. Barraket, J., and Furneaux, C. (2012). Social innovation and social enterprise: Evidence from Australia. Franz, H. W., Hochgerner, J., and Howaldt, J. (eds.), Challenge Social Innovation, pp. 215-237. Berlin Heidelberg: Springer.

9. Bedwell, W.L., Fiore, S.M. and Salas, E., (2013). Developing the future workforce: An approach for integrating interpersonal skills into the MBA classroom, Academy of Management Learning \& Education, 13(2), 171-186.

10.Casey, T. and Dustmann, C. (2010). Immigrants' identity, economic outcomes and the transmission of identity across generations. The Economic Journal, 120(542), F31 - F51.

11.Cedefop (Centre Européen pour le Développement de la Formation Professionnelle) Glossary (2016). Retrived May 25, 2016 from: http://euskillspanorama.cedefop.europa.eu/Glossary/.

12. Chartered Institute of Personnel Development (2016). The psychological contract. Retrieved from http://www.cipd.co.uk/hr-resources/factsheets/psychological-contract.aspx.

13.Chivaura, V. G. (2007). "Hunhu/Ubuntu: A sustainable approach to endogenous development, bio-cultural diversity and protection of the environment in Africa". Haverkort, B. and Rist, S. (eds), Endogenous development and bio-cultural diversity: the interplay between worldviews, globalization and locality. Compas Series on Worldviews and Sciences No. 6, pp. $229-240$.

14.Collett, E. and Zuleeg, F. (2008). Soft, scarce, and super skills: Sourcing the next generation of migrant workers in Europe. Migration Policy Institute (www. migrationpolicy. org/transatlantic/scarceskills. pdf).

15.Dall'Amico, E., and Verona, S. (2015). Cross-Country Survey on Soft Skills Mostly Required by Companies to Medium/High Skilled Migrants: Methodological approach for a common framework of Soft Skills at work. Ceipiemonte S.c.p.a., for Valorize High Skills Migrant (VHSM) Project, No. 2014-1-IT02KA204-003515. Torino, Italy.

16.Damm, A.P. (2009). "Ethnic enclaves and immigrant labor market outcomes: Quasi-Experimental Evidence". Journal of Labor Economics 27.2, 281-314.

17.Delors, J. (1996). Learning: The Treasure Within. Report to UNESCO of the International.

18.Commission on Education for the Twenty-first Century. Paris: UNESCO.

19.Driedger, L. (1989). The Ethnic Factor: Identity in Diversity. Toronto: McGraw-Hill Ryerson.

20.Dustmann, Christian, Albrecht, Glitz, and Uta, Schönberg (2009). "Job search networks and ethnic segregation in the workplace". University College London, Working Paper.

21.Erickson, T. (2008). Plugged in: the Generation Y guide to thriving at work. Harvard Business School Publishing: Boston, MA.

22.Espejo, R., \& Dominici, G. (2017). Cybernetics of Value Cocreation for Product Development. Systems Research and Behavioral Science, 34, $24-40$.

23.European Framework (2007). The Key Competences for Lifelong Learning - A European Framework. Recommendation of the European Parliament and of the Council of 18 December 2006 on key competences for lifelong learning. Luxembourg: Office for Official Publications of the European Communities.

24.Foged, M. and Peri, G. (2015). Immigrants' Effect on Native Workers: New Analysis on Longitudinal Data. IZA Discussion Papers, No. 8961. Bonn, Germany: Institute for the Study of Labor (IZA).

25.Franz, H. W., Hochgerner, J., and Howaldt, J. (2012). Challenge social innovation: An introduction. Franz, H. W., Hochgerner, J., and Howaldt, J (eds.), Challenge Social Innovation, pp. 1-16. Berlin Heidelberg: Springer.

26.Geertz, C. (1973). The Interpretation of Cultures: Selected Essays. New York: Basic Books.

27.Gunasekara, A., Rajendran, D., and Grant, S. (2015). Job Satisfaction of Sri Lankan and Indian Skilled Migrants in the Australian Workplace. Australian Journal of Business and Economic Studies, 1(2), 60 - 71.

28.Halász, G., and Michel, A. (2011). Key Competences in Europe: interpretation, policy formulation and implementation. European Journal of Education, 46.3, 289-306.

29.Hawkins, O. (2015). Migration statistics, House of Commons Library (available on: www.parliament.uk/briefing-papers/sn06077.pdf).

30.Heckman, J. and Kautz, T. (2013). Fostering and measuring skills: interventions that improve character and cognition. National Bureau of Economic Research (Working Paper No. 19656. Cambridge, MA: National Bureau of Economic Research.

31.Hilbert, Christoph, and Klaus, Schömann (2004). "The need for early identification of future skill requirements in the European Union". Identifying skill needs for the future: From research to policy and practice, Reference Series 52, 50-62.

32.Institute_of_Employment_Studies (2006).Employers' Use of Migrant Labor. Home Office Report 03/06. London: Home Office. 
33.Jackson, M.C. (2003). Systems Thinking: Creative Holism for Managers. Chichester, West Sussex, England, and Hoboken, NJ.: John Wiley.

34.Kapsali, M. (2011). How to implement innovation policies through projects successfully. Technovation, $31(12), 615-626$.

35.Kloosterman, R.C., and Rath, J. (2001). "Immigrant entrepreneurs in advanced economies: mixed embeddedness further explored", Journal of Ethnic and Migration Studies, 27(2), 189-201.

36. Kuznetsov, Y. and Sabel, C., 2006. International migration of talent, diaspora networks, and development: Overview of main issues. Diaspora networks and the international migration of skills: How countries can draw on their talent abroad, pp.3-20.

37.Larin, S. J. (2010). Conceptual debates in ethnicity, nationalism, and migration. The International Studies Encyclopedia, pp. 438-457.

38.Lepeley, M.-T. and Albornoz, C.A. (2012). Advancing People Skills for 21st Century Business Education in Chile. Alon, I., Jones, V. and McIntyre, J. (eEds.), Innovation in Business Education in Emerging Countries, Palgrave Macmillan, New York, p. forthcoming.

39.Luong, F. (2016). The Crisis of Western Democracies and National Identity: Citizenship, Immigration, and Constitutional Patriotism. Verdugo, R.N., and Milne, A. (eds.), National Identity: Theory and Research, pp, 153 - 176. Information Age Publishing, Charlotte, NC.

40.Mason, P.L. (2009). Culture matters: America's African Diaspora and labor market outcomes. Munich: Personal RePEc Archive.

41.Massaro, M., Bardy, R., Lepeley, M.T. and Dal Mas, F. (2014). Intellectual capital development in Business Schools. The role of 'soft skills' in Italian Business Schools, Proceedings of the 5th European Conference on Intellectual Capital, Academic Publishing Limited, Reading, pp. 1-8.

42.Massaro, M., Bardy, R. and Garlatti, A. (2015). A Soft Skill Training Model for Executive Education. Lepeley, M.T. Kimakowitz, E. von, and Bardy, eds. Human Centered Management in Executive Education: Global Imperatives, Innovation and New Directions. New York: Palgrave MacMillan, 2016, pp. 222 - 241.

43.Maturana, H.R. and Varela, F.J. (1980). Autopoiesis and Cognition: The Realization of the Living. Dordrecht et al.: Reidel Publishing Company.

44.Meister, J. C., and Willyerd, K. (2010). Mentoring millennials. Harvard Business Review, 88(5), 1-5.

45.Mulgan, G., Tucker, S., Ali, R., \& Sander, B. (2007). Social innovation: What it is, why it matters and how can it be accelerated. Oxford: Skoll Centre for Social Entrepreneurship.

46.Newenham-Kahindi, A. (2009). The Transfer of Ubuntu and Indaba Business Models Abroad: A Case of South African Multinational Banks and Telecommunication Services in Tanzania. International Journal of Cross Cultural Management, 9.1, 87-108.

47.OECD (Organization for Economic Co-operation and Development) (2001). Defining and Selecting Key Competences. Paris: OECD; (2005). Executive summary of the DeSeCo study. Retrieved May 20, 2016, from http:// www.oecd.org/dataoecd/47/61/35070367.pdf; (2015). How will the refugee surge affect the European economy? Retrieved May 20, 2016, from http://www.oecd.org/migration/How-will-the-refugeesurge-affect-the-European-economy.pdf.

48. Olopade, D. (2015). 'The Bright Continent Breaking Rules and Making Change in Modern Africa. New York: Houghton Mifflin Harcourt.

49.Peri, G. (2102). The effect of immigration on productivity: Evidence from US states. Review of Economics and Statistics, 94.1, 348-358.

50.Rametsteiner, E., Weiss, G. (2006). Assessing policies from a systems perspective - experiences with applied innovation systems analysis and implications for policy evaluation. Forest Policy and Economics, $8,564-576$.

51.Raphael, S. and Ronconi, L. (2007). The effects of labor market competition with immigrants on the wages and employment of natives. Du Bois Review, 4.2, 413-432.

52.Robotham, D. and Jubb, R. (1996). Competences : measuring the unmeasurable, Management Development Review, 9(5), 25-29.

53.Ruhs, M., and Vargas-Silva, C. (2011). "The labour market effects of immigration". The Migration Observatory at the University of Oxford Briefing.

54.Salganik, L.H., and Rychen, D. S. (2003). Key competencies for a Successful Life and a Well-functioning Society. Göttingen:, Hogrefe \& Huber Publishers.

55.Shandler, D. (2009). Motivating the millennial knowledge worker: Help today's workforce succeed in today's economy. Crisp Publications: Seattle, WA. 
56.Santos, D. and Primi, R. (2014). Social and emotional development and school learning: a measurement proposal in support of public policy. Preliminary results of the Social and Emotional Skills Measurement Project in Rio de Janeiro. Sao Paulo: OECD/ Ayrton Senna Institute/Secretaria de Educação Rio de Janeiro.

57.Silitshena, R. M. K. (1992). Botswana: a physical, social and economic geography. Gaborone, Botswana.

58.Stirling, A. (2015). Migrant employment outcomes in European labour markets. IPPR ( Institute for Public Policy Research) Report. http://www. ippr. org/publications/migrant-employment-outcomes-ineuropeanlabour-markets.

59.Tapscott, D. (2009). Grown up digital: How the Net Generation is changing your world. McGraw-Hill: New York, NY.

60.Thompson, C., and Gregory, J. B. (2012). Managing millennials: A framework for improving attraction, motivation, and retention. The Psychologist-Manager Journal, 15(4), 237-246.

61.Todericiu, R., Şerban, A., and Dumitraşcu, O. (2013). Particularities of knowledge workers' motivation strategies in Romanian organizations. Procedia Economics and Finance, 6(13), 405-413.

62.Valentinov, V. (2015). From equilibrium to autopoiesis: a Luhmannian reading of Veblenian evolutionary economics. Economic Systems, 39(1), 143-155.

63.Williams, A., and Baláž, V. (2014). International migration and knowledge. Abingdon-on-Thames Routledge.

64.Williams, A. (2007). Listen to me, learn with me: International migration and knowledge. British Journal of Industrial Relations, 45(2), 361-82.

65.Williams Prendergast, M. (2009). Newcomers to Ireland: an evaluation of the challenges facing Irish organisations in the management of their multicultural workforces in terms of training and development (Doctoral dissertation, University of Leicester).

66. Wye, Chung-Khain, and Yet-Mee, Lim (2009). Perception differential between employers and undergraduates on the importance of employability skills. International education studies, 2(1), 95-105. 